\title{
Utility of blood procalcitonin concentration in the management of cancer patients with infections
}

\author{
This article was published in the following Dove Press journal: \\ OncoTargets and Therapy \\ 22 January 2016 \\ Number of times this article has been viewed
}

\author{
Bonita Durnaś',2 \\ Marzena Wątek' \\ Tomasz Wollny' \\ Katarzyna Niemirowicz ${ }^{3}$ \\ Michał Marzec ${ }^{4}$ \\ Robert Bucki 2,3 \\ Stanisław Góźdźl \\ 'Holy Cross Oncology Center \\ of Kielce, Artwińskiego, Kielce, \\ Poland; ${ }^{2}$ Department of Physiology, \\ Pathophysiology and Microbiology \\ of Infections, The Faculty of Health \\ Sciences of the Jan Kochanowski \\ University in Kielce, Aleja IX Wieków \\ Kielc, Kielce, Poland; ${ }^{3}$ Department of \\ Microbiological and Nanobiomedical \\ Engineering, Medical University \\ of Bialystok, Bialystok, Poland; \\ ${ }^{4}$ Department of Pathology and \\ Laboratory Medicine, University of \\ Pennsylvania, Philadelphia, PA, USA
}

Correspondence: Robert Bucki Department of Microbiological and Nanobiomedical Engineering, Medical University of Bialystok, Mickiewicza 2c, I5-222 Bialystok, Poland

Tel +48 857485483

Fax +48 857485416

Email buckirobert@gmail.com

\begin{abstract}
Diagnosis of infections in cancer patients is usually problematic since differentiating between infection and fever of unknown origin is often a considerable clinical challenge. In general, increase concentration of blood procalcitonin (PCT) is associated with severe bacterial infection. PCT with an optimal cutoff level of $0.5 \mathrm{ng} / \mathrm{mL}$ seems to be the most helpful biochemical parameter in detecting severe infections, mainly bloodstream infection, in patients with hematological cancers. In all clinical situations, the elevated level of PCT should be carefully analyzed, always with a thorough physical examination and an appropriate microbiological assessment.
\end{abstract}

Keywords: procalcitonin, cancer, infection

\section{Biological functions of PCT}

Treatment and supportive care of patients with hematological malignances and solid tumors often requires the management of systemic and localized infections. They remain a significant cause of excess morbidity and premature mortality especially among cancer patients with neutropenia. As in this group of patients, infections can occur with minimal signs and symptoms and progress rapidly, early detection and appropriate empirical antimicrobial treatment is crucial to survival. Initial evaluation of these patients includes physical examination, hematological and biochemical analysis, microbiological cultures, and chest radiography if infection of respiratory tract is suspected. ${ }^{1}$ Unfortunately, in many cases microbiological cultures are negative, and laboratory tests such as an abnormal leukocyte count and elevated C-reactive protein (CRP) concentration or expression of proinflammatory cytokines (IL-8, IL-6, TNF $\alpha$ ) may be nonspecific. ${ }^{2}$ In recent years, some new useful tools and markers have been proposed for better diagnosis of severe infections. Some of them are polymerase chain reaction, a technique that permits better detection of some microorganisms like intracellular bacteria, noncoding RNAs, and specific markers for infections such as procalcitonin (PCT), which was first introduced in medical literature in $1975 .{ }^{3}$ PCT is a 116-amino acid prohormone of calcitonin (CT) and is produced mainly by C-cells of the thyroid gland. It has a molecular weight of $13 \mathrm{kDa}^{4}$ In healthy state or in the absence of infections, its blood level is very low $(<0.1 \mathrm{ng} / \mathrm{mL})$. In case of infection, this protein is synthesized in liver, lung, kidney, intestine, and almost all other tissues throughout the body. Physiological and inflammatory PCT is coded by the same CALC-I gene, located on chromosome 11 . A recent report hypothesized that sepsis-associated increase of PCT is mediated by stimulus-specific factors within the promoter of this gene. ${ }^{4}$ The inflammatory PCT is proteolytic cleaved by neither intracellular nor plasma enzymes. So if PCT is secreted into the circulation, it remains there unchanged, with a half-life of 25-30 hours. For this reason, PCT has been termed as hormokine. ${ }^{4}$ The production of PCT during inflammation can be

submit your manuscript $\mid$ www.dovepress.con 
A

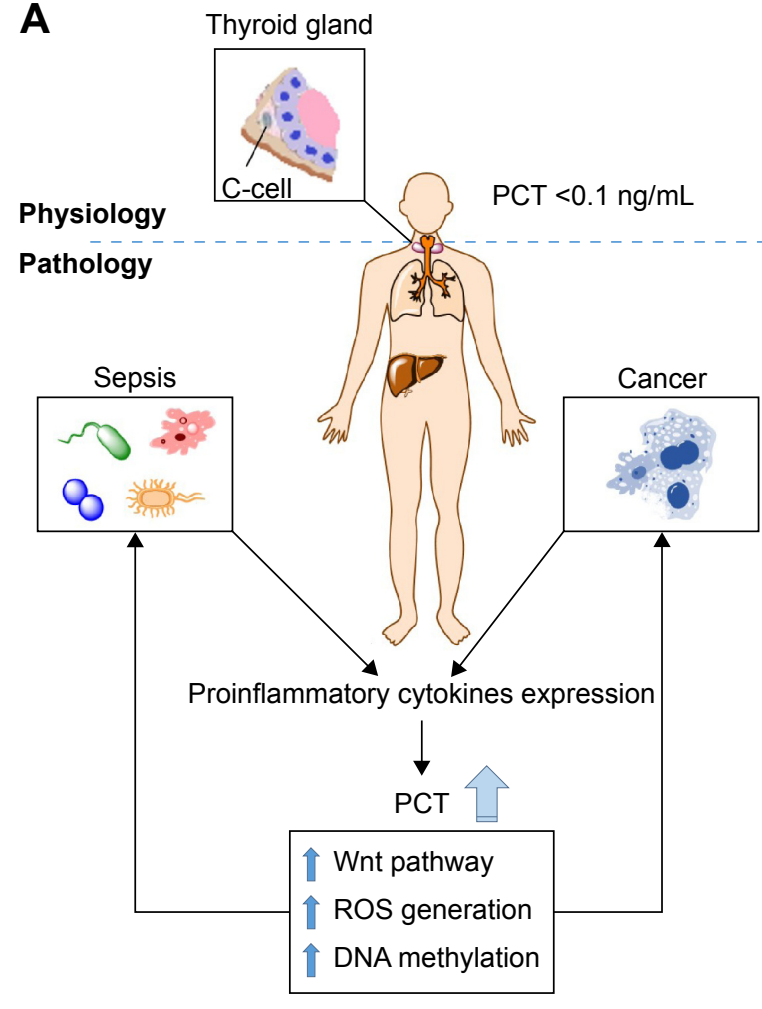

B

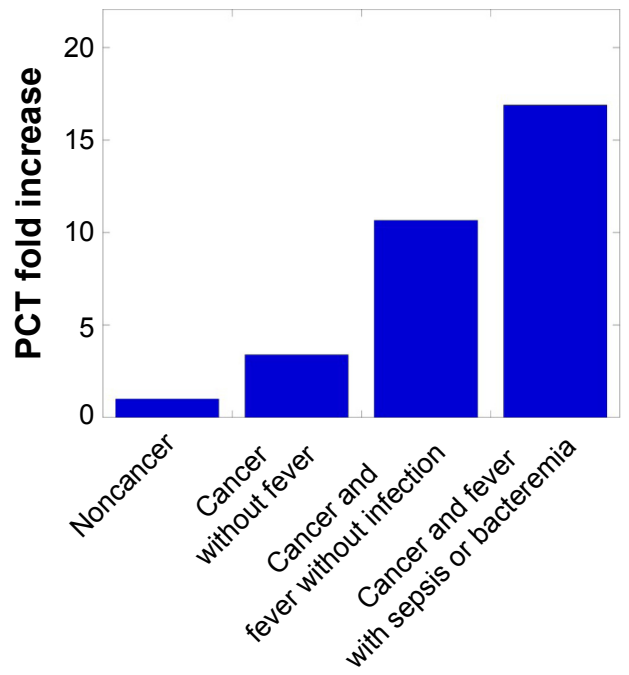

Figure I Secretion and biological function of PCT in physiological and pathological stage (A). Differentiation fold increase in PCT level among patients who developed a cancer with or without fever or/and microbiological infection (B).

Notes: Median of PCT level: 0.029 - noncancer patients; 0.099 - patients with cancer without fever; 0.310 - patients with cancer and fever without microbiological infection; 0.490 - patients with cancer and fever with bacteremia/sepsis. Adapted from Chaftari AM, Hachem R, Reitzel R, et al. Role of procalcitonin and interleukin-6 in predicting cancer, and its progression independent of infection. PLoS One. 20I5;10(7):e0I30999. ${ }^{37}$

Abbreviations: PCT, procalcitonin; ROS, reactive oxygen species.

induced by the bacterial endotoxin of gram-negative bacteria or by proinflammatory cytokines (eg, IL-1 and IL-6 or TNF $\alpha$ ) (Figure 1A). ${ }^{5}$ The effect of bacterial endotoxin on PCT levels in normal human volunteers has been investigated by Dandona et al. ${ }^{6}$ The PCT concentration, which was undetectable at 0,1 , and 2 hours after endotoxin injection, was detectable at 4 hours and peaked at 6 hours, maintaining a plateau through 8 and 24 hours following injection. However, at the same time range, the elevation of CT concentrations was not observed. ${ }^{6}$ Besides the fact that PCT is a marker of inflammation, data from Preas et $\mathrm{al}^{7}$ show that anti-inflammatory agents like ibuprofen might modulate the PCT level, indicating its potential toxic nature during inflammation development. The hypothetical mechanisms suggesting that PCT might work as a toxic mediator include different pathways such as upregulation of the Wnt pathway, increase in production of reactive oxygen species, and association with DNA methylation (Figure 1A). ${ }^{8}$

\section{PCT in different inflammatory conditions}

Many clinical studies have documented the utility of PCT in diagnosis of different inflammatory diseases. It has been reported that PCT is elevated in bacterial, fungal, and protozoal infections, but not in viral infections. The highest plasma levels of PCT are observed in severe, acute bacterial infections, mainly bloodstream infections (BSIs) or sepsis. Sepsis from bacterial infections, triggered by the release of endotoxins composed of lipopolysaccharide or lipoteichoic acid molecules from the outer wall of gram-negative or grampositive bacteria, respectively, is a major cause of human death for which there is no effective treatment once the complex inflammatory pathways stimulated by these amphipathic molecules are activated. ${ }^{9}$ A correlation of PCT with severity of sepsis was observed, and in patients without bacteremia or systemic infections, PCT levels are low or only slightly elevated. ${ }^{10}$ Many studies have been performed to determine the PCT's cutoff value for predicting bacteremia. Usually, the value of $0.5 \mathrm{ng} / \mathrm{mL}$ is used to rule out BSI. ${ }^{11}$ However, higher cutoff value at $0.9 \mathrm{ng} / \mathrm{mL}$ was proposed by Hattori et al. ${ }^{12}$ It should be noted that the renal function may influence the PCT level in both noninfected and infected patients. ${ }^{12}$ High serum PCT concentration is closely associated with infection caused by gram-negative rods than by gram-positive cocci. Nakajima et $\mathrm{al}^{11}$ suggested that PCT level might be used in 
predicting the type of causative pathogen in patients with sepsis. For good sensitivity and specificity of such determination, they proposed a cutoff value of PCT at $16.9 \mathrm{ng} / \mathrm{mL}$. These findings are in accordance with reports published earlier, suggesting that such differences are caused by the fact that gram-positive and gram-negative bacteria elicit inflammatory responses that rely on different signaling pathways of the innate immune system. ${ }^{13}$ To distinguish blood contamination from BSI due to coagulase-negative staphylococci PCT can also be helpful. Patients with BSI have higher PCT concentration than those with blood contamination, and so the cutoff of $0.1 \mathrm{ng} / \mathrm{mL}$ has a high sensitivity to exclude true infection. ${ }^{14}$ The utility of PCT has also been studied as a diagnostic marker for lower respiratory tract infections. At initial diagnosis stage in patients with pulmonary tuberculosis, PCT serum concentrations as well as CRP were significantly lower compared to levels observed with other bacterial community-acquired pneumonia (CAP) and diseases that are caused by atypical pathogens like Mycoplasma pneumoniae. Chlamydia pneumoniae induced lower PCT levels compared to classical bacteria such as Streptococcus pneumoniae. ${ }^{15}$ Muller et al ${ }^{16}$ proposed to use PCT measurement as a complement analysis for diagnosis of CAP at the time of admission to an emergency department. Elevated PCT concentration can help assess the severity of illness, predict bacteremia, and start antibiotics administration. If an infiltrate on chest radiograph and acute respiratory symptoms are accompanied with low PCT levels $(<0.1 \mu \mathrm{g} / \mathrm{mL})$, an alternative diagnosis to the "typical" pneumonia should be taken into consideration. ${ }^{16}$ However, PCT may be insufficient as a diagnostic marker for pneumonia because only some patients with pneumonia exhibited higher PCT levels (more than $0.5 \mathrm{ng} / \mathrm{mL}$ ). In patients with localized infections without signs of systemic manifestation, PCT may not be or may be only slightly increased. ${ }^{11}$ Besides BSI and pneumonia, the utility of PCT evaluation has also been proposed for endocarditis, meningitis, bacterial peritonitis, and serious Clostridium difficile infections. ${ }^{17-20} \mathrm{PCT}$ was also proposed as a marker of some candidosis. A cutoff for PCT level ( $\leq 6.08 \mathrm{ng} / \mathrm{mL}$ ) to rule out the presence of Candida spp., with a high negative predictive value, was suggested. In effect, PCT can be considered as a diagnostic tool to exclude the presence of Candida spp. in BSI of critically ill patients, and it can be helpful in limitation of unnecessary use of antifungal agents. ${ }^{21}$ On the other hand, there are data suggesting that PCT level should not be recommended for the diagnosis of fungal infections. Montagna et $\mathrm{al}^{22}$ concluded that PCT values from 0.5 to $1 \mathrm{ng} / \mathrm{mL}$ cannot be considered as a reliable indicator of fungal sepsis and that low values of PCT cannot exclude this infection in neonatal patients admitted to intensive care unit. In one study, 55 cases of proven or probable invasive fungal infection in adult patients were analyzed, and in the early phase of infection, PCT was elevated in fewer than half of the invasive candidiasis episodes and in only 1 patient with invasive aspergillosis. ${ }^{23}$ The increase of serum PCT was also reported after burns, multiple trauma, major surgery, or cardiogenic shock. In multiple trauma as well as in burned patients, PCT induction during the early posttraumatic period differs according to the severity of tissue injury. ${ }^{24} \mathrm{~A}$ study examined 175 patients suffering from burn injury and showed that average PCT levels of above $2 \mathrm{ng} / \mathrm{mL}$ measured within 48 hours after burn injury predicted sepsis and mortality and indicated that, in these situations, the administration of prophylactic antibiotics should be considered. ${ }^{25}$ In patients undergoing surgery, moderate PCT increase can be observed after minor and aseptic surgery, whereas higher PCT levels frequently occur after intestinal, cardiac, and thoracic operations. Furthermore, after elective surgery, high postsurgical plasma PCT levels are related to a higher rate of complications. In patients with infections compared to patients with normal recovery, PCT concentration is significantly higher. Because PCT concentrations can be periodically elevated after operation, its measurement postoperatively can improve patient management and can be helpful in prediction of serious infections, only when the range of PCT concentrations are followed up. ${ }^{26,27}$ Picariello et $\mathrm{al}^{28}$ reported that $\mathrm{PCT}$ concentrations measured at the time of admission to the cardiac critical care unit have been elevated in patients with cardiogenic shock in the presence of multiple organ failure and in the absence of signs of infections (PCT levels $\geq 1.0 \mathrm{ng} / \mathrm{mL}$ ). In survivors, a progressive reduction in PCT values was observed, whereas the lack of changes in PCT concentrations was documented in those who died. This observation indicates that serial PCT measurements might be more reliable than a single assessment of PCT level. ${ }^{28}$ In all the above-mentioned situations, PCT level correlates with the severity of injury and local tissue inflammation. In the absence of a further insult that might induce PCT production, this biomarker's level returns rapidly to its normal value. When the inflammation in the traumatized tissue disappears, PCT level soon declines toward its normal range and no complications are observed. In systemic inflammation, sepsis, or organ dysfunction, there is a continuous stimulus for the systemic production of PCT, so PCT level remains elevated. ${ }^{24}$ It has also been shown that serum PCT levels are higher in patients with chronic renal insufficiency 
and that these levels decrease after dialysis. Nevertheless, dialysis patients without infection have higher PCT concentrations than the "standard" cutoff of $0.5 \mathrm{ng} / \mathrm{mL}$. Thus, in patients with renal dysfunction, a serum PCT cutoff of $0.75 \mathrm{ng} / \mathrm{mL}$ appears to be more appropriate for the diagnosis of infection. ${ }^{29}$ In febrile patients with autoimmune diseases, PCT is a useful marker to distinguish bacterial sepsis from disease flare. ${ }^{30}$ Also in patients with arthritis, the level of PCT in serum and/or joint fluid can be used in distinguishing septic arthritis from noninfectious forms of arthritis. ${ }^{31}$ In these clinical situations, PCT test may be valuable in choosing patients who require antibiotics treatment.

\section{PCT in cancer patients}

The clinical interpretation of elevated PCT concentration in blood represents a great challenge in cancer patients since its values might be influenced by several factors such as the presence of metastasis or neuroendocrine function of malignant tissue (eg, small-cell lung cancer). In these cases, PCT concentrations can be elevated regardless of infections, manifesting a poor specificity for bacterial infection. ${ }^{32}$ PCT and CT levels are also elevated in patients with medullary thyroid cancer (MTC), and both these proteins are considered to be markers for this disease. A significant correlation between CT and PCT has been observed in patients with MTC, but not in infections. In contrast to $\mathrm{CT}, \mathrm{PCT}$ is more stable and specific in both serum and plasma. PCT measurement is cheaper and more easily available in many hospital laboratories, so it is a good alternative to CT measurement for the management of patients with MTC. ${ }^{33}$ Reported PCT concentrations in patients with generalized metastatic disease are inconsistent. Matzaraki et $\mathrm{al}^{34}$ indicated that patients with solid tumors, metastasis, and no evidence of infection had markedly elevated PCT levels, especially those with generalized metastatic disease. The authors proposed that PCT may serve as an early indicator for the progression of neoplastic disease ${ }^{34}$ However, these findings are in contrast to the report of Giovanella et al, ${ }^{35}$ which demonstrated that solid carcinoma at different stages "per se" did not result in elevated circulating PCT concentrations above $0.5 \mathrm{ng} / \mathrm{mL}$. In this study, a population of 390 aseptic patients with breast, head and neck, ovary, cervix, and non-small-cell lung carcinoma, with or without metastasis were examined. Patients with neuroendocrine tumors, renal failure, serum CRP above $5 \mathrm{ng} / \mathrm{mL}$, sepsis, and other infectious or inflammatory diseases were excluded. The use of the fluorodeoxyglucose positron-emission tomography, a very accurate method for screening of infections or other inflammatory diseases, was a strong point of this study. As a result, only patients without infections were enrolled. The authors suppose that the elevated PCT concentrations in patients with generalized metastatic disease in the Matzaraki study could be connected with coexisting occult infections because not only PCT but also CRP and white blood cell (WBC) were elevated. ${ }^{35}$ Thus, the interpretation of elevated PCT levels in cancer patients is difficult and sometimes not clear. It has also been observed that in patients who experienced massive tumor lysis and cytokine release following therapy with monoclonal antibodies, the PCT concentrations may reach values of two digits. $^{36}$ The utility of PCT to discriminate between fever caused by infection and inflammation has been intensively studied in cancer patients - especially in those with solid tumors and hematological diseases (Figure 1B). ${ }^{37}$ As far as cancer patients with solid tumors and without neutropenia are concerned, conclusions about the utility of PCT measurement considerably differ. Some reports claim that PCT can help in differentiating between infection and no infection, but others state that its role is limited and should be interpreted with caution. In the Shomali et al study ${ }^{38}$ where 248 patients with fever and solid tumors, lymphoma, and multiple myeloma, but without neutropenia, were analyzed, patients with stage IV cancer or metastasis had significantly higher baseline PCT levels than did those with early stages of cancer or those in remission. This finding indicates that not only is PCT specific for bacterial infection but that it also may be a predictor of metastasis and advanced cancer in patients with no suspicion of BSI (no fever or chills). Elevated concentration of PCT is most suggestive of BSI and sepsis in cancer patients with no metastasis. The discriminatory power of PCT is more suitable for bacteremia or sepsis, whereas it fails to discriminate minor, localized infections from tumor-related or liver metastasis-related fever. In patients with localized infections, the mean PCT levels were not higher compared to PCT levels in patients without infections. ${ }^{38} \mathrm{~A}$ similar conclusion might be made based on Diness et al's study, ${ }^{39}$ where the median PCT concentration was higher in patients with infection and metastatic disease than in patients with infection and localized cancer. Diness's study recruited 25 patients with infection. Among them, eleven had PCT in the normal range, of whom five had a radiologically verified infection and six had a microbiologically verified infection (positive blood culture and urine culture). They concluded that PCT within normal range could not exclude an infection and that it is probably not superior to CRP. Accordingly, PCT cannot be treated as a standard marker of bacterial infection in patients with solid tumors. ${ }^{39}$ 
However, in contrast to the above-mentioned report, some studies have shown superiority of PCT over CRP in the diagnosis and follow-up of infectious diseases in cancer patients. It has been shown that serum PCT measurement may be useful in exclusion of infections in non-small-cell lung cancer patients and that it is better than CRP ${ }^{40}$ Similarly, Yaegashi et $\mathrm{al}^{41}$ have investigated patients with advanced urological cancer. PCT, in contrast to CRP and WBC level, can help discriminate between bacterial infections and nonbacterial infections, mainly in neoplastic fever. ${ }^{41}$

Numerous clinical studies have shown that PCT is a sensitive and specific marker of sepsis in patients with febrile neutropenia. PCT seems to be more useful in this population than in cancer patients without neutropenia. Some of these studies focused on patients with hematological malignances, but there are also reports that address this issue in patients with solid tumors and neutropenic fever. In a prospective study by Jimeno et al, ${ }^{42}$ the efficacy of baseline PCT levels in the detection of bacteremia and in the prediction of outcome in patients with solid tumors undergoing chemotherapy who developed fever and neutropenia has been assessed. The median baseline PCT values were significantly higher in patients who had febrile neutropenia with bacteremia compared with patients who had fever of unknown origin (FUO). PCT also helps identify patients with an increased likelihood of treatment failure. The optimal PCT cutoff value to differentiate between infections and FUO was $0.5 \mathrm{ng} / \mathrm{mL} .^{42}$ These findings are consistent with those of Kim et al, ${ }^{43}$ who studied 286 cancer patients ( 239 with solid tumors and 47 with hematologic malignancies) with febrile neutropenia. PCT with a cutoff value of $0.5 \mathrm{ng} / \mathrm{mL}$ and tachypnea were independently and significantly associated with bacteremia. These findings suggest that PCT is a useful early diagnostic marker to detect bacteremia in cancer patients with febrile neutropenia and that PCT has better diagnostic value than CRP. ${ }^{43}$ The utility of PCT measurement in hemato-oncological patients has also been presented in Sandri et al's ${ }^{44}$ report. PCT measurement just after fever onset could be a useful tool to discriminate patients with bacterial infection and patients with FUO. The highest concentrations of PCT were observed in individuals with bacteremia caused by gram-negative rods in contrast to those with Staphylococcus coagulase-negative bacteremia. In patients with documented infections, PCT was increased in leukopenic patients as well as in those with normal WBC count. ${ }^{44}$ To improve the diagnosis of infection, some investigators recommend repeat measurements of PCT, especially in patients treated for acute hematological malignances where periods of neutropenia following chemotherapy are usually longer than in patients with solid tumor. Gac et al ${ }^{45}$ proposed to start PCT sampling on the first day of chemotherapy, and then follow it up every 4 days until the end of neutropenia. They observed that during the neutropenic episode with bacteremia, PCT reached the level of $0.5 \mathrm{ng} / \mathrm{mL}$, which might be used as a cutoff value. Those serial PCT measurements are an important tool which can predict bacteremia after chemotherapy. ${ }^{45}$ Similarly Carnino et $a{ }^{46}$ tried to determine if PCT level can be used as a predictive marker of infections in asymptomatic patients before onset of the fever. They observed patients with solid or hematological disorder and neutropenia induced by chemotherapy. Serum PCT levels were measured when leukocytes were at the lowest level and on the third day, when patients were checked for any signs of infections. The authors observed that PCT levels correlated with the type of neoplastic disorder. In patients with hematological malignances and severe neutropenia (especially in those with acute leukemia), PCT levels were higher than in patients affected by solid tumors. No differences were observed between PCT concentrations in patients who subsequently developed a localized infection and those who did not. In contrast to the previous study, the authors of this report suggested that the PCT is not a good preemptive marker of infection in neutropenic asymptomatic cancer patients, in whom localized infections occur frequently. The investigators try to explain it as follows: in such infections PCT starts to rise, when the process become systemic and when PCT is released not from leukocytes in the site of localized infection but from parenchymal cells mainly by hepatocytes. However, PCT can help in excluding systemic evolution of a localized infection and in identifying patients who can be safely treated as outpatients. ${ }^{46}$

\section{Conclusion and perspective for the future}

In summary, evaluation of blood PCT might be very helpful in the management of cancer patients who frequently suffer from infections, but clinicians should be aware of some interpretative problems and limitations. In general, the highest plasma levels of PCT are observed in severe, acute bacterial infections, mainly BSI, but it could be also elevated in infection-independent conditions (multiple trauma, major surgery, cardiogenic shock) and in the presence of metastasis or carcinoma with a neuroendocrine component. In patients with solid tumors, combined measurement of PCT and IL-6 might be even used as indicators for progression of neoplastic diseases, especially liver metastasis. Because PCT increases earlier in cancer patients with bacterial infections and returns 
more quickly to the normal range than CRP (it has a shorter half-life), it should be considered as better marker in the differential diagnosis. However, PCT lacks both specificity and positive predictive value to be considered as an ideal biomarker of infection. PCT with an optimal cutoff level of $0.5 \mathrm{ng} / \mathrm{mL}$ seems to be the most helpful indicator of severe infections, mainly BSI. On the other hand, PCT levels are usually low or only slightly elevated in patients with small, localized infections and in cases where infection is caused by atypical bacteria. Its diagnostic value in fungal infections is also controversial. So, PCT measurement is most helpful in prediction of serious infections only when the range of PCT concentrations is followed up.

Physicians should always remember that biomarkers do not replace a thorough clinical evaluation of the patient, and hence PCT levels should be assessed only in the context of a physical examination and when appropriate microbiological diagnostic is performed. The introduction of assays for PCT helps physicians monitor infections, start antibiotic therapy, and if infection is excluded, limit the number of prescriptions for antibiotics. Very likely, in the future, more than one or two markers of infections in connection with traditional and novel methods of rapid microorganism identification may be a good practice in the management of patients with febrile neutropenia. A recent study shows the application of magnetic nanoparticles (MNP) to concentrate pathogens or their molecules to reach the detection limit of currently used immunodetection assays. ${ }^{47}$ Moreover, based on differences of MNP spectra when attached to pathogens, new rapid diagnostic microbiological methods might be developed. In addition, some new biomarkers have already been evaluated. One of them is proadrenomedullin, which seems to be better than PCT, in identifying localized infections in hematological patients, where such infections could be undetectable by conventional microbiologic techniques. ${ }^{48}$ Promising results were also obtained for evaluation of circulating miRNA levels in the diagnosis of sepsis. ${ }^{3}$ Many recent results indicate that high miRNA levels have been recognized as specific for sepsis. ${ }^{3}$

\section{Disclosure}

The authors report no conflicts of interest in this work.

\section{References}

1. Urabe A. Clinical features of the neutropenic host: definitions and initial evaluation. Clin Infect Dis. 2004;39(Suppl 1):S53-S55.

2. Stoppelkamp S, Veseli K, Stang K, Schlensak C, Wendel HP, Walker T. Identification of predictive early biomarkers for Sterile-SIRS after cardiovascular surgery. PLoS One. 2015;10(8):e0135527.

3. Dumache R, Rogobete AF, Bedreag OH, et al. Use of miRNAs as biomarkers in sepsis. Anal Cell Pathol (Amst). 2015;2015:186716.
4. Liu HH, Guo JB, Geng Y, Su L. Procalcitonin: present and future. Ir J Med Sci. 2015;184(3):597-605.

5. Maruna P, Nedelnikova K, Gurlich R. Physiology and genetics of procalcitonin. Physiol Res. 2000;49(Suppl 1):S57-S61.

6. Dandona P, Nix D, Wilson MF, et al. Procalcitonin increase after endotoxin injection in normal subjects. J Clin Endocrinol Metab. 1994; 79(6):1605-1608.

7. Preas HL, Nylen ES, Snider RH, et al. Effects of anti-inflammatory agents on serum levels of calcitonin precursors during human experimental endotoxemia. J Infect Dis. 2001;184(3):373-376.

8. Panico C, Nylen E. Procalcitonin beyond the acute phase: novel biomediator properties? BMC Med. 2013;11:189.

9. Schefold JC, Bierbrauer J, Weber-Carstens S. Intensive care unitacquired weakness (ICUAW) and muscle wasting in critically ill patients with severe sepsis and septic shock. J Cachexia Sarcopenia Muscle. 2010;1(2):147-157.

10. Assicot M, Gendrel D, Carsin H, Raymond J, Guilbaud J, Bohuon C. High serum procalcitonin concentrations in patients with sepsis and infection. Lancet. 1993;341(8844):515-518.

11. Nakajima A, Yazawa J, Sugiki D, et al. Clinical utility of procalcitonin as a marker of sepsis: a potential predictor of causative pathogens. Intern Med. 2014;53(14):1497-1503.

12. Hattori T, Nishiyama $\mathrm{H}$, Kato $\mathrm{H}$, et al. Clinical value of procalcitonin for patients with suspected bloodstream infection. Am J Clin Pathol. 2014;141(1):43-51.

13. Charles PE, Ladoire $S$, Aho $S$, et al. Serum procalcitonin elevation in critically ill patients at the onset of bacteremia caused by either Gram negative or Gram positive bacteria. BMC Infect Dis. 2008;8:38.

14. Schuetz P, Mueller B, Trampuz A. Serum procalcitonin for discrimination of blood contamination from bloodstream infection due to coagulase-negative staphylococci. Infection. 2007;35(5):352-355.

15. Kang YA, Kwon SY, Yoon HI, Lee JH, Lee CT. Role of C-reactive protein and procalcitonin in differentiation of tuberculosis from bacterial community acquired pneumonia. Korean J Intern Med. 2009; 24(4):337-342.

16. Muller B, Harbarth S, Stolz D, et al. Diagnostic and prognostic accuracy of clinical and laboratory parameters in community-acquired pneumonia. BMC Infect Dis. 2007;7:10.

17. Cornelissen CG, Frechen DA, Schreiner K, Marx N, Kruger S. Inflammatory parameters and prediction of prognosis in infective endocarditis. BMC Infect Dis. 2013;13:272.

18. Viallon A, Desseigne N, Marjollet O, et al. Meningitis in adult patients with a negative direct cerebrospinal fluid examination: value of cytochemical markers for differential diagnosis. Crit Care. 2011;15(3):R136.

19. Yang SK, Xiao L, Zhang H, et al. Significance of serum procalcitonin as biomarker for detection of bacterial peritonitis: a systematic review and meta-analysis. BMC Infect Dis. 2014;14:452.

20. Rao K, Walk ST, Micic D, et al. Procalcitonin levels associate with severity of Clostridium difficile infection. PloS One. 2013;8(3):e58265.

21. Cortegiani A, Russotto V, Montalto F, et al. Procalcitonin as a marker of candida species detection by blood culture and polymerase chain reaction in septic patients. BMC Anesthesiol. 2014;14:9.

22. Montagna MT, Coretti C, Rella A, et al. The role of procalcitonin in neonatal intensive care unit patients with candidemia. Folia Microbiol. 2013;58(1):27-31.

23. Dornbusch HJ, Strenger V, Kerbl R, et al. Procalcitonin - a marker of invasive fungal infection? Support Care Cancer. 2005;13(5):343-346.

24. Meisner M, Adina H, Schmidt J. Correlation of procalcitonin and $\mathrm{C}$-reactive protein to inflammation, complications, and outcome during the intensive care unit course of multiple-trauma patients. Crit Care. 2006;10(1):R1.

25. Kim HS, Yang HT, Hur J, et al. Procalcitonin levels within 48 hours after burn injury as a prognostic factor. Ann Clin Lab Sci. 2012;42(1): $57-64$.

26. Meisner M, Tschaikowsky K, Hutzler A, Schick C, Schuttler J. Postoperative plasma concentrations of procalcitonin after different types of surgery. Intensive Care Med. 1998;24(7):680-684. 
27. Li Y, Jin ZC, Cai Y, Ji MS, Liu J. Value of serum procalcitonin in evaluating the prognosis of sepsis in elderly patients with colorectal cancer undergoing emergency colorectal surgery. Indian J Surg. 2013;75(2):86-93.

28. Picariello C, Lazzeri C, Chiostri M, Gensini GF, Valente S. Kinetic of procalcitonin in patients with cardiogenic shock following acute myocardial infarction: preliminary data. HSR Proc Intensive Care Cardiovasc Anesth. 2010;2(3):201-207.

29. Lee WS, Kang DW, Back JH, Kim HL, Chung JH, Shin BC. Cut-off value of serum procalcitonin as a diagnostic biomarker of infection in end-stage renal disease patients. Korean J Intern Med. 2015; 30(2):198-204

30. Wu JY, Lee SH, Shen CJ, et al. Use of serum procalcitonin to detect bacterial infection in patients with autoimmune diseases: a systematic review and meta-analysis. Arthritis Rheum. 2012;64(9):3034-3042.

31. Wang C, Zhong D, Liao Q, Kong L, Liu A, Xiao H. Procalcitonin levels in fresh serum and fresh synovial fluid for the differential diagnosis of knee septic arthritis from rheumatoid arthritis, osteoarthritis and gouty arthritis. Exp Ther Med. 2014;8(4):1075-1080.

32. Patout M, Salaun M, Brunel V, Bota S, Cauliez B, Thiberville L. Diagnostic and prognostic value of serum procalcitonin concentrations in primary lung cancers. Clin Biochem. 2014;47(18):263-267.

33. Kaczka K, Mikosinski S, Fendler W, Celnik A, Pomorski L. Calcitonin and procalcitonin in patients with medullary thyroid cancer or bacterial infection. Adv Clin Exp Med. 2012;21(2):169-178.

34. Matzaraki V, Alexandraki KI, Venetsanou K, et al. Evaluation of serum procalcitonin and interleukin-6 levels as markers of liver metastasis. Clin Biochem. 2007;40(5-6):336-342.

35. Giovanella L, Suriano S, Ricci R, Ravani P, Ceriani L. Circulating procalcitonin in aseptic carcinoma patients: a specificity study with (18) F-fluorodeoxyglucose positron-emission tomography/computed tomography as benchmark. Clin Chem Lab Med. 2010;48(8):1163-1165.

36. Schuttrumpf S, Binder L, Hagemann T, Berkovic D, Trumper L, Binder C. Utility of procalcitonin concentration in the evaluation of patients with malignant diseases and elevated C-reactive protein plasma concentrations. Clin Infect Dis. 2006;43(4):468-473.

37. Chaftari AM, Hachem R, Reitzel R, et al. Role of procalcitonin and interleukin-6 in predicting cancer, and its progression independent of infection. PLoS One. 2015;10(7):e0130999.
38. Shomali W, Hachem R, Chaftari AM, et al. Can procalcitonin distinguish infectious fever from tumor-related fever in non-neutropenic cancer patients? Cancer. 2012;118(23):5823-5829.

39. Diness LV, Maraldo MV, Mortensen CE, Mellemgaard A, Larsen FO. Procalcitonin and C-reactive protein as markers of bacterial infection in patients with solid tumours. Dan Med J. 2014;61(12):A4984.

40. Tulek B, Koylu H, Kanat F, Arslan U, Ozer F. Serum C-reactive protein and procalcitonin levels in non-small cell lung cancer patients. Contemp Oncol (Pozn). 2013;17(1):68-72.

41. Yaegashi H, Izumi K, Kitagawa Y, et al. Differential diagnosis between bacterial infection and neoplastic fever in patients with advanced urological cancer: the role of procalcitonin. Int J Urol. 2014; 21(1):104-106.

42. Jimeno A, Garcia-Velasco A, del Val O, et al. Assessment of procalcitonin as a diagnostic and prognostic marker in patients with solid tumors and febrile neutropenia. Cancer. 2004;100(11):2462-2469.

43. Kim DY, Lee YS, Ahn S, Chun YH, Lim KS. The usefulness of procalcitonin and C-reactive protein as early diagnostic markers of bacteremia in cancer patients with febrile neutropenia. Cancer Res Treat. 2011;43(3):176-180.

44. Sandri MT, Passerini R, Leon ME, et al. Procalcitonin as a useful marker of infection in hemato-oncological patients with fever. Anticancer Res. 2008;28(5B):3061-3065.

45. Gac AC, Parienti JJ, Chantepie S, et al. Dynamics of procalcitonin and bacteremia in neutropenic adults with acute myeloid leukemia. Leuk Res. 2011;35(10):1294-1296.

46. Carnino L, Betteto S, Loiacono M, et al. Procalcitonin as a predictive marker of infections in chemoinduced neutropenia. J Cancer Res Clin Oncol. 2010;136(4):611-615.

47. Niemirowicz K, Swiecicka I, Wilczewska AZ, et al. Growth arrest and rapid capture of select pathogens following magnetic nanoparticle treatment. Colloids Surf B Biointerfaces. 2015;131:29-38.

48. Al Shuaibi M, Bahu RR, Chaftari AM, et al. Pro-adrenomedullin as a novel biomarker for predicting infections and response to antimicrobials in febrile patients with hematologic malignancies. Clin Infect Dis 2013;56(7):943-950.
OncoTargets and Therapy

\section{Publish your work in this journal}

OncoTargets and Therapy is an international, peer-reviewed, open access journal focusing on the pathological basis of all cancers, potential targets for therapy and treatment protocols employed to improve the management of cancer patients. The journal also focuses on the impact of management programs and new therapeutic agents and protocols on

\section{Dovepress}

patient perspectives such as quality of life, adherence and satisfaction. The manuscript management system is completely online and includes a very quick and fair peer-review system, which is all easy to use. Visit http://www.dovepress.com/testimonials.php to read real quotes from published authors. 